\title{
PERSPECTIVES IN SYSTEM THERMAL-HYDRAULICS
}

\author{
F. D'AURIA \\ GRNSPG - University of Pisa \\ Via Livornese 1291, San Piero a Grado - 56100 Pisa, Italy \\ E-mail : dauria@ing.unipi.it \\ Received November 20, 2012
}

The paper deals with three main topics: a) the definition of System Thermal-Hydraulics (SYS TH), b) a historical outline for SYS TH and, c) the description of elements for reflection when planning research projects or improvement activities, this last topic being the main reason for the paper. Distinctions between basic thermal-hydraulics and computational FluidDynamics (CFD) on the one side and SYS TH on the other side are considered under the first topic; stakeholders in the technology are identified. The proposal of Interim Acceptance Criteria for Emergency Core Cooling Systems in 1971 by US NRC (AEC at the time) is recognized as the starting date or the triggering event for SYS TH (second topic). The complex codes and the main experimental programs (list provided in the paper) constitute the pillars for SYS TH. Caution or warning statements are introduced in advance when discussing the third topic: a single person (or a researcher) has little to no possibility, or capability, of streamlining the forthcoming investments or to propose a roadmap for future activities. Nevertheless, the ambitious attempt to foresee developments in this area has been pursued without constraints connected with the availability of funds and with industrial benefits or interests. Demonstrating the acceptability of current SYS TH limitations and training in the application of those codes are mentioned as the main challenges for forthcoming research activities.

KEYWORDS : System Thermal-hydraulics, Licensing of NPP

\section{INTRODUCTION}

Thermal-hydraulics and system thermal-hydraulics (SYS TH) shall be seen as one of the five key disciplines essential for progress in nuclear science, making reference to Nuclear Power Plant (NPP) design and Nuclear Reactor Safety (NRS) technologies. The other disciplines may be identified as neutron physics, structural mechanics, radioprotection, and reliability including statistics.

SYS TH deserves and achieves proper attention by national and international institutions engaged in NPP design and NRS. This is also true from the sides of research and development (R \& D) and innovation. As a consequence, the opinion of a single author related to 'perspectives-for-development', as in the present case, shall be discussed within suitable frameworks: in other words, a one-author paper with the current title (Perspectives in System Thermal-hydraulics) may appear ambitious, singleminded and impractical.

Therefore, motivations are proposed hereafter to justify the paper. Reference is made to developments in complex technologies (SYS TH in the present case) which may require multi-million dollar investment to achieve concrete improvements. A few even contradictory concepts are discussed in the next paragraphs.

The epoch which started two or three decades ago is characterized by a fast increase in ease of travel and in communication power: in these conditions, joint decisions and institutional agreements may have contributed to average but also to overshadow the ideas of individuals. In the areas of science and technology, including planning for the future, joint decisions constitute a democratic process. This also minimizes the resources needed for development and, in general terms, is functional in getting the peace of the humankind. However, the ideas of individuals in research and innovations remain the engine for commercial success and advancements specifically when noncomplex technologies or fragments of complex technologies are involved.

The political and strategic importance of NPP design, construction and operation, and of NRS with main reference to the needs to satisfy acceptance criteria set by regulators (e.g. 10 CFR 50.46, ref. [1]) makes it necessary: a) to construct and to operate scaled facilities having 'suitableachievable' power, pressure and geometric dimensions as part of the design, and b) to develop and to qualify sophisticated computer codes (or computational tools). Endeavors associated with both SYS TH facilities and computational tools unavoidably involve research groups formed by dozens of researchers and corresponding financial investments. The role of individuals is typically supportive inside those contexts and their own ideas are not pushed in case these are in contrast with the objectives of the group and with the available resources. 
Then, one may settle that:

- Averaging from several decision makers is a democratic process and the 'fashion-of-the-period' activities are privileged for funding.

- Targets set by individuals may become part of a dictatorial process if approved for development and may experience difficulties for fund raising; therefore, targets set by individuals may remain hidden.

- (Brilliant) ideas of individuals may be overshadowed when important projects are concerned in complex technologies.

All of this constitutes the background and partly the motivation for the present paper. The objective is to provide a historical perspective for system thermal-hydraulics distinguishing between basic thermal-hydraulics and system thermal-hydraulics and to characterize possible perspectives in the development without constraints as budget, time schedules, 'current-fashion', roadmaps of established and on-going projects and strategies of the major stake-holders in the sector. So, the implementation of the proposals, necessarily incomplete and not systematic, shaped in the paper is expected difficult and the practical relevance of those proposals may reveal questionable.

It seems worthwhile to establish a framework for key actors and stake-holders in nuclear reactor thermalhydraulics. The list below may give an idea:

1) Authors of textbooks: El-Wakil, Tong-Weisman, Hsu, Collier, Lahey-Moody, Ishii, Todreas-Kazimi, and Levy are notorious scientists who contributed, via books spread all over the world, to the establishment of nuclear reactor thermal-hydraulics technology.

2) US NRC (US Nuclear Regulatory Commission): the role was to establish targets for the acceptability of NPP, consequently requesting a suitable level of knowledge and understanding in SYS TH.

3) International Institutions, namely OECD/NEA (Organization for Economic Cooperation and Development / Nuclear Energy Agency) and IAEA (International Atomic Energy Agency) which have the role to fix the status of knowledge, to spread the same knowledge as well as to identify perspectives for development.

4) National Institutions, primarily EC (European Commission) and US DOE (US Department of Energy), but not only those: their key role was to finance research in thermal-hydraulics based on suggestions coming from the member parties or those who were selected as consultants for R \& D investment strategies.

5) The nuclear Industry, including vendors, designers (primarily, but not only Westinghouse, General Electric, Areva-Siemens-Framatome and Babcock \& Wilcox), and utilities (primarily, but not only EPRI and $\mathrm{EdF}$ ) financed $\mathrm{R} \& \mathrm{D}$ in different sectors of thermal-hydraulics with objectives to both address regulatory needs and to create profit by better design.

6) The NURETH (Nuclear Reactor Thermal-hydraulics) series of conferences within the framework of the ANS (American Nuclear Society), started in 1980 (NURETH-01) with the fifteenth event (NURETH15) to be held in 2013, can be used to synthesize the state of the art and the progress in this area: around 4000 papers co-authored by more than 5000 scientists have been part of the proceedings of 15 conferences.

7) A dozen Journals publish nuclear reactor thermalhydraulics papers. Reference Journals in the previous century for nuclear SYS TH (see list of acronyms) were NED, NT, ANE and PNE. More recently other journals have been established and publish papers in the area, such as STNI and NET. Fundamentals of thermal-hydraulics can be also found in ETFS, IJMF and JHT.

The above list shall be considered to estimate the complexity of the endeavor of shaping the future for nuclear reactor thermal-hydraulics.

\section{FLASH HISTORY FOR SYSTEM THERMAL- HYDRAULICS AND TRENDS}

Reference is made to thermal-hydraulics as a discipline adopted in nuclear reactor technology and to needs coming from the design and the safety assessment of NPP.

\subsection{Definition}

The distinction between basic thermal-hydraulics, system thermal-hydraulics (SYS TH) and Computational Fluid-dynamics (CFD) in single and two phase flow is concerned hereafter. This is done with the understanding that unanimously accepted boundaries between those three sectors of knowledge do not exist and without the willingness to impose (un-necessary) new definitions.

- Thermal-hydraulics makes reference to single and two phase mixture performance whenever individual fluid or multi-fluids in steady and transient conditions are concerned. Different fields can be involved in each phase. The numerical domain for the solution of equations is assumed to be bounded by a solid surface and can be 'one-point' (giving rise to zerodimensional or lumped-parameter models), onedimensional, two-dimensional or three-dimensional. The solid-surface-bounding hypothesis is straightforward for zero-dimensional and one-dimensional situations and a virtual solid surface may be considered in the two-dimensional and the three-dimensional situations. Pursuing the numerical solution inside solid bounded regions is known as the porous media approach, or finite space averaged approach.

- System thermal-hydraulics (SYS TH) makes reference to geometry, materials and boundary conditions which characterize a NPP. Experimental (or test) 
facilities (TF) and computational tools constitute pillars in SYS TH. In the case of TF, Integral Test Facilities (ITF) and Separate Effects Test Facilities (SETF) shall be distinguished. ITF aim at 'reproducing' (typically scaling-down) the overall Reactor Coolant System performance and the SETF aim at 'reproducing' limited space regions or components of the NPP during limited time periods following an accident. In the case of computational tools, the code and the input deck (or nodalisation) shall be distinguished. Furthermore, the SYS TH code includes neutron kinetics and I \& C modeling capability. Qualification activities involving the so called scaling issue shall be addressed in relation to the design of ITF and SETF and of the related experiments as well as in relation to the computational tools, e.g. refs. [2] and [3].

The following key branches in SYS TH can be distinguished, where the word 'code' implies modeling and numerics developments and the word 'experiment' implies a suitable data base:

- Code1: SYS TH (codes),

- Code2: Sub-channel (codes),

- Code3: Containment (codes),

- Code4: Specific phenomena, components, steady state core and CHF (codes),

- Experiment1: data from NPP measurements,

- Experiment2: data from properly scaled ITF,

- Experiment3: data from properly scaled SETF and selected 'basic' experiments.

- Computational Fluid-dynamics (CFD) primarily makes reference to single phase fluid-dynamics and heat transfer. The two phase capability for CFD is available, but is far from being suitable for industrial needs for a broad range of applications; therefore, the two-phase capability of CFD is neglected here. The numerical domain for the solution of equations is un-bounded. Three dimensional geometry is adopted for the integration of the equations. The turbulence phenomenon has a direct connection with solved equations and calculated unknowns. The linear dimension of the integration domain can be as small as $1 / 10 \mathrm{~mm}$. Variation profiles for quantities like velocity can be calculated inside a pipe for a cross section orthogonal to the flow axis. Pursuing the numerical solution in the un-bounded fluid regions is known as the open media approach.

The key difference between basic thermal-hydraulics and CFD may be identified as the modeling approach for two-phase mixtures and the related capability. When addressing the single phase flow, geometry averaging assumptions adopted in thermal-hydraulics are not needed for CFD. The turbulence is calculated directly only in the case of CFD. Furthermore, reducing the mesh (or calculation region) dimension is expected to bring to convergence only in the case of CFD.

The difference between SYS TH and basic thermal- hydraulics mostly applies when experiments and computational tool validation processes are planned. SYS TH implies the process of identification and characterization of phenomena which are relevant to the conditions of NPP, e.g. refs. [4], [5] and [6]

\subsection{The History}

The history of nuclear thermal-hydraulics shall start with the E. Fermi pile in 1942 (Dec. $2^{\text {nd }}$ ): several tons of graphite were assembled in the pile having a cross section $>20 \mathrm{~m}^{2}$ in order to ensure suitable thermal capacity for dissipating the thermal power possibly produced by the chain fission reaction (other than to minimize neutron leakages).

Afterwards, the design, construction, and operation of energy systems in the range from a few $\mathrm{KW}$ to thousands of MW was possible with a parallel and consistent development of the thermal-hydraulics discipline.

\section{Before 1960}

Accidents and related scenarios in nuclear power plants were considered to demonstrate the safety of NPP in the 1950s when computers did not exist. Experiments, pioneering thermal-hydraulics models, and engineering evaluations were the basis of reactor safety analyses at the time.

Nuclear thermal-hydraulics and reactor physics (or neutron kinetics), as well as nuclear fuel materials, were the subjects of integrated studies.

$\underline{1960-1970}$

Systematic thermal-hydraulic studies and experiments were conducted in the 1960 s, noticeably concerning individual 'physical' phenomena like two-phase critical flow, critical heat flux, depressurization and blow-down. Thermalhydraulics became a 'self-standing' discipline.

Several small scale fundamental programs were launched and completed.

New findings from those research projects were considered in reactor safety and licensing documents.

\section{0-1980}

Massive use of computers for nuclear reactor safety started in the 1970s. The accident analysis could also benefit from primitive (SYS TH) numerical codes and from measurements taken in integral-system experiments. The nuclear regulatory point-of-view was established with the publication of the 'Interim Acceptance Criteria for ECCS' (1971), ref. [7]. This triggered a wide variety of research aimed at the evaluation of safety margins and focusing on the estimation of the maximum temperature on the surface of fuel rods following large break loss of coolant accidents (LB-LOCA). Appendix K to paragraph 10 CFR-50.46 (Code of Federal Regulation) followed in 1974. The publication of the 'Interim Acceptance Criteria for ECCS' shall be taken as the starting date for SYS TH: competences were requested to comply with those criteria.

The technological community and the industry reacted to the request by regulators: comprehensive research projects were started in the experimental area as well as in the area of code development. Large experimental facilities were 
designed and operated and the SYS TH codes were made available for transient analyses in NRS.

Large scale experimental ITF implied international cooperation projects and 'relevant' measured data were gathered to understand transient system thermal-hydraulic performance.

TPCF (Two-Phase Critical Flow) and CHF/DNB (Critical Heat Flux / Departure from Nucleate Boiling) can be identified as the key thermal-hydraulic phenomena of interest during the decade associated with the LBLOCA (Large Break Loss of Coolant Accident) event.

'Conservatism' is the keyword which characterizes the application of Appendix K (to 10 CFR 50.46) in licensing analyses. During the same decade WASH-1400 or the "Rasmussen Report" was issued, putting the basis for the application of PSA in NRS; significant results from the execution of probabilistic analyses were produced, ref. [8].

At the end of the decade, in 1979, the Three Mile Island Unit 2 accident happened. In the area of SYS TH, this shifted the attention from LBLOCA to SBLOCA phenomena.

1980-1990

Within the framework of SYS TH code use, V \& V (Verification and Validation) was soon recognized, e.g. ref. [9], as a mandatory process to be completed before application of those computational tools to safety and licensing. In this context, the basis was set for addressing the scaling issue, e.g. ref. [3] (see also section 3 below). The reference SYS TH codes are APROS**, ATHLET*, CATHARE*, KORSAR*, MARS**, RELAP*, SPACE**, TRAC* TRACE $^{* *}$ (where: $*=$ precursor code; $* *=$ lately developed code).

International activities were conducted at CSNI (Committee on the Safety of Nuclear Installations of OECD/ NEA, Organization for Economic Cooperation and Development/Nuclear Energy Agency) proposing viable ways for $\mathrm{V} \& \mathrm{~V}$, refs. [4], [5] and [6]. The importance of user effect upon the predictions was recognized, refs. [10], [11] and [12], as well as the role of the input deck (or nodalization) and of the related qualification, e.g. ref. [13].

The contribution to the understanding of important NRS phenomena from ITF experimental programs, conducted or initiated during this decade shall be realized. Key acronyms for the ITF or large scale SETF, within BWR, PWR and CANDU technologies (related research programs may have developed in decades different from the current one in the cases identified by an asterisk: however, for the sake of synthesis all major research programs in SYS TH are listed hereafter in alphabetic order), are: APEX*, ATLAS*, BETHSY, CCTF, FIST, FIX-II, GIRAFFE, HDR, ISB, LOBI, LOFT, LSTF, MARVIKEN, MIST, PACTEL, PANDA, PIPER-ONE, PKL, PMK, PSB*, PUMA, RD14M, ROSA, SCTF, SEMISCALE, SPES, UM, THTF, and UPTF. In this framework, the 2D/3D international cooperation program, ref. [14] (involving the already mentioned UPTF, SCTF and CCTF), provided key information to address the scaling issue, i.e. connecting the measured data with expected NPP conditions, from the experimental viewpoint. Enormous benefits were gained in the area of demonstrating SYS TH code capabilities.

CCFL (Countercurrent Flow Limitation) and NC (Natural Circulation) can be identified as the key thermalhydraulic phenomena of interest during the decade associated with the SBLOCA (Small Break Loss of Coolant Accident) event, together with reflood. The thermalhydraulics of ECCS (Emergency Core Cooling Systems) shall be mentioned in this context.

The words SYS TH were proposed inside the scientific community. Later on, use of these words spread.

The need for uncertainty methods suitable for predicting unavoidable errors to be added to the results of calculations performed by system thermal-hydraulic codes became clear at the beginning of the 1990s (or even at the end of the 1980s). Working approaches were proposed; noticeably, the pioneering effort by USNRC shall be mentioned, ref. [15], which lead to the formulation of CSAU (Code Scaling and Applicability Uncertainty). The PIRT process was proposed (see also below).

In the middle of the decade, in 1986, the Chernobyl Unit 4 accident happened. In the area of SYS TH, this moved increased attention toward passive systems and the processes for the design of AP-600 and SBWR had a strong impulse.

1990-2000

Addressing the uncertainty in SYS TH as a follow-up of $\mathrm{V} \& \mathrm{~V}$ was the center of attention in this period. Following and considering the CSAU, the Wilks formulation and the UMAE (Uncertainty Methodology based on Accuracy Extrapolation) were proposed, refs. [16] and [17]. The UMS (Uncertainty Method Study) project was launched by the CSNI in 1993 and completed in 1998, ref. [18]: the fundamental features of the uncertainty methods were described in detail and a suitable demonstration was achieved in relation to their robustness and qualification level.

The US NRC issued the Regulatory Guide (RG) 1.157 , ref. [19]: the application of system thermal-hydraulic codes was envisaged, even though recommending the use of selected conservative models. Those models are concerned with phenomenological areas where the knowledge was not considered satisfactory. Requirements in the RG 1.157 did allow a few attempts at practical applications. However, Appendix K to 10 CFR 50.46 continued to be used during the decade for licensing purposes. The acronym BEPU (Best Estimate Plus Uncertainty) started to circulate.

A break-through workshop for planning the future in SYS TH was held in Annapolis (1996) under the combined effort by OECD/NEA and US NRC. The development of a new SYS TH code was launched (current name is TRACE), following identification of inadequacies in existing codes at the time. Notably, the key words 'Internal Assessment of Uncertainty' were proposed during the workshop. At the end of the decade, the CIAU method (Code with capability of Internal Assessment of Uncertainty) was developed, ref. [20] and ready for practical applications. CIAU used UMAE (mentioned before) as the 'engine' and the qualification tool for the process of code application. 
The development of CFD (Computation Fluid Dynamic) technology, mostly connected with single-phase flows, had a strong impulse, made possible with the increase in computational power, ref. [21].

The SYS TH coupling with three-dimensional neutron physics was also made possible by the availability of more powerful computers and numerical techniques, ref. [22].

2000-2010

Application of BEPU approaches in licensing processes, implying the exploitation of the capabilities of SYS TH codes and of UM, definitely started in the 2000s. The following key events, not an exhaustive list, not in the order of importance, not in the order of time, see also ref. [23], give an idea of the technology developments in the area:

a) The AREVA (NPP designer) on the behalf of the ETN (Brazilian utility owner for the nuclear plant) proposed a BEPU methodology to analyze the LBLOCA for the licensing of Angra-2 NPP in Brazil, ref. [24]. The submission was analyzed by the regulatory authority of Brazil which also requested the application of different uncertainty methods by assessors independent from AREVA.

b) USNRC issued the RG 1.203, ref. [25], which provided clarification of the regulatory expectation for transient and accident analysis including the application of BEPU approaches.

c) CSNI launched and completed the six-year project BEMUSE. The aim was to demonstrate the maturity of uncertainty methods and approaches with main concern to LBLOCA applications. The objective was achieved, but differences in the results by participants (mainly in predicting reflood time) caused the need for a careful interpretation of related findings. The difficulty in harmonizing, from the side of applicants of uncertainty methods, the choice of input uncertainty parameters and the related ranges of variations was an outcome from the project.

d) Three important BEPU-concerned documents were issued by IAEA, two Safety Report Series, SRS 23 (already mentioned) and SRS 52, refs. [2] and [26], and one Specific Safety Guide, SSG-2, ref. [27]. The SRS 52 deals with the description of workable uncertainty approaches and methods. The SSG-2, dealing with Deterministic Safety Analysis (DSA) in general, proposes the BEPU approach in licensing as consistent with the technological state of the art in the area of accident analysis.

e) Best estimate (BE) conferences, BE-2000 and BE2004, refs. [28] and [29], were held under the auspices of the American Nuclear Society (ANS). This series of conferences was actually continued by V \& V Workshops in the US in Idaho Falls (Idaho) in 2008, Myrtle Beach (North Carolina) in 2010, and Las Vegas (Nevada) in 2012, with the cooperation of the nuclear sector of the ASME.

f) The BEAU (application of the Best Estimate Analysis and Uncertainty) method was proposed by Canadian experts, ref. [30].

g) A variety of BEPU (it shall be clear that the BEPU acronym is not always adopted) applications all over the world during the concerned decade, mostly within the license renewal framework, are summarized in ref. [31].

The first decade of the current millennium is characterized by the application in NRS technology of the expertise in thermal-hydraulics: the BEPU approach constitutes the key word in this connection. The 2010s decade started with the submission of Chapter 15 of the FSAR (Final Safety Analysis Report) of the Atucha-II NPP to the regulatory authority in Argentina, by the NA-SA utility. In this case, the entire chapter of the FSAR is based on the BEPU and the approach itself was submitted in advance and endorsed by the regulatory body, ref. [32].

Key words for the TH spot historic outline can be found in Table 1. In the first row, the key 'actors' and the 'stakeholders' for the nuclear thermal-hydraulics discipline are listed as derived by the items 1) to 7) in the Introduction.

\subsection{An Interpretation of the Current Trends}

There are important research projects and initiatives in progress in the area of SYS TH which also imply future plans and perspectives. A non-systematic and (maybe) incomplete list of relevant programs, projects or activityframeworks includes:

- Recent or on-going projects on the side of EC: EUROFASTNET, NURESIM, NURISP and NURESAFE.

- On-going project on the side of US DOE: CASL.

- OECD/NEA (CSNI \& NSC) activities or projects: UAM, PREMIUM, W-Gama initiatives including ISP, 'VVER-1000 Kalinin addressing NPP 3D measurements' and 'Oskarshamn-II addressing the BWR stability issue'.

- IAEA planning and carrying out CRP and TM, namely in the areas of BEPU, connection DSA-PSA, CFD for NRS and thermal-hydraulics of innovative systems including SMR.

- US NRC supporting the development of SYS TH codes (e.g. TRACE) and running the related CAMP program, other than continuously evaluating new reactors and updating the licensing process (in this last case with a number of connections to TH).

- ATLAS, MARS and SPACE projects in Korea, that are an integrated approach to SYS TH, involving experiments, modeling, and numerical development.

- China and India designing and building or even operating large scale thermal-hydraulic facilities and, China primarily, developing new system codes.

- FONESYS and SILENCE networks, established and recently launched, in the areas of code development and experimental programs, respectively.

Typical subjects for activities envisaged or in progress include: 
Table 1. Key Words for a Spot Historic Outline of System Thermal-hydraulics

\begin{tabular}{|c|c|c|c|c|}
\hline \multicolumn{2}{|c|}{ ACTORS \& STAKE-HOLDERS* } & $\rightarrow$ & \multicolumn{2}{|c|}{$\begin{array}{l}\text { Authors of Textbooks, US NRC, International \& National Institutions, Industry, } \\
\text { NURETH (Conferences), Journals }\end{array}$} \\
\hline $\begin{array}{l}\text { PERIOD OR } \\
\text { EVENT }\end{array}$ & \multicolumn{3}{|c|}{ KEY WORDS/PHENOMENA } & KEY DOCUMENT \\
\hline $\begin{array}{c}\text { Fermi Fission } \\
\text { Reaction (1942) }\end{array}$ & \multicolumn{3}{|c|}{ Thermal Capacity (of graphite). } & \\
\hline Up to 1960 & \multicolumn{3}{|c|}{ Heat Transfer \& Pressure Drops. } & E.g.: Dittus-Boelter eq. for HTC, Multiplier Approach for TPPD. \\
\hline $1960-1970$ & \multicolumn{3}{|c|}{$\begin{array}{l}\text { TH Fundamentals; TPCF; Blow-down; } \\
\text { CHF/DNB. }\end{array}$} & E.g.: Moody and H-F models for TPCF, LUT for CHF. \\
\hline $1970-1980$ & \multicolumn{3}{|c|}{$\begin{array}{l}\text { LBLOCA - Conservatism; TPCF; } \\
\text { CHF/DNB; Code Design. }\end{array}$} & USNRC IAC for ECCS, App. K to 10 CFR 50.46. \\
\hline $1980-1990$ & \multicolumn{3}{|c|}{$\begin{array}{l}\text { SBLOCA - BE; V \& V \& Scaling; 2D/3D; } \\
\text { CCFL; NC; Code Validation. }\end{array}$} & CSAU, USNRC Compendium, CSNI SOAR on TECC, CCVM-ITF \\
\hline $1990-2000$ & \multicolumn{3}{|c|}{$\begin{array}{c}\text { AM; CFD; UM; Code Validation \& } \\
\text { Application. }\end{array}$} & CCVM-SETF, UMS**, USNRRC RG ${ }_{-} 1.157$, UMAE, GRS-method \\
\hline $2000-2010$ & \multirow{2}{*}{\multicolumn{3}{|c|}{$\begin{array}{l}\text { Licensing: BEPU (Code Application) \& } \\
\text { Scaling; Passive System Thermal- } \\
\text { hydraulics. }\end{array}$}} & $\begin{array}{l}\text { USNRC RG 1.203, IAEA SRS } 23 \text { and 52, IAEA SSG-2, } \\
\text { BEMUSE**, NURESIM**, NURISP**, CASL** }\end{array}$ \\
\hline 2012 & & & & \\
\hline After 2012 & \multicolumn{3}{|c|}{ Consolidation in the above areas. $* * *$} & NURESAFE**, CASL, PREMIUM*** \\
\hline
\end{tabular}

*See Introduction. ** Acronym for an International Project. *** See Chapter 3

- Improvement in CHF database and understanding.

- Improvement in reflood understanding.

- Improvement in understanding the role of spacer grids.

- Finalizing, as far as possible, the development of IA transport models.

- Coupling of SYS TH with other branches of nuclear technology: 3D NK, structural mechanics, nuclear fuel, etc.

- Improvement in CFD modeling including two-phase.

- Addressing the V \& V of CFD.

- Modeling of CRUD deposition.

- Connection DSA-PSA.

- Use of BE techniques in PSA.

- Operation of experimental ITF or large scale facilities, e.g. in Finland (PACTEL), Germany (PKL-III), Japan (LSTF), Korea (ATLAS), Switzerland (PANDA), and Russia (PSB).

\section{THE NEEDS IN SYS TH: A PERSONAL VIEW}

The historic outline in the previous section as well as the expectably incomplete list of key actors and stakeholders, provide a picture of the "thermal-hydraulics universe' and of its complexity (section 2.2 and Table 1). A broad set of activities is already going on (section 2.3) in the same framework. Thus, the destiny of any individual or personal position for perspectives may turn out to be impractical and unusable, as also discussed in the Introduction.

However, looking from an optimistic viewpoint and in the attempt to invite the reader to a (further) reflection, the list of needs below is prepared. The concerned domains for investigation include modeling features of computational tools, validation and application of those tools, and planning of experiments. The list unavoidably reflects the personal experience of the author and shall not be seen as in competition with any ongoing international projects or with any similar list supported by proper contexts.

\subsection{The Envisaged Needs}

The envisaged needs in system thermal-hydraulics, or better, elements for reflection, other than bringing personal views in relation to specific topics, may need elaboration and details beyond that which is possible in a paper (at least, that which was possible for the present paper).

No attempt has been made to provide an order of importance for the issues concerned below. Commonly, this has been done in the past by adopting PIRT or related techniques. The present author always expressed his doubts in relation to the use of the 'ranking' process in SYS TH. Now, this quote by the key proponent of the PIRT process, Novak Zuber , ref. [33], “... the PIRT process as presently implemented produces absolutely useless documents ... ranking is based purely on subjective opinions ...", put those doubts in the right perspective. Therefore, priority classification of the items below is left to the reader, if deemed necessary.

Fifteen elements for reflection or issues (or Category / Target for improvement) are listed below. Interferences among the issues could not be avoided although an attempt 
is made in this direction. A description of each 'element' is provided and a rough proposal is formulated for dealing with ideas to address the issue.

1) The 'local form loss' coefficients (also reported as 'K-factors' hereafter)

The K-factor is the multiplicative term to the product $\rho w^{2}$ (where ' $\rho$ ' is the 'reference' density and ' $w$ ' is the 'reference' velocity of the concerned fluid) to calculate pressure drops at geometric discontinuities.

The origin of the issue is connected with the derivation of the balance equations at the hearth of SYS TH codes: the balance equations are derived making reference to a geometric space without discontinuities (some advancement is proposed for the integration domain by TRACE code, but this is insufficient for practical applications). Therefore, the missing information about form loss coefficients at geometric discontinuities, either in the forward fluid motion direction (typically, nominal conditions) or in the reverse direction (possibly expected in case of transient) must be fixed by the analyst or code-user. In a few situations tabulated (pre-calculated) or experimental data exist. In the largest majority of conditions the user must consider analogies with those data and/or "invent" a value based on his or her expertise: the user has almost no possibility to estimate the effect of the not-fully developed flow upon the value of the ' $\mathrm{K}$-factor'. An additional source of misunderstanding (related to the values of ' $\mathrm{K}$-factors') derives from the inherent difficulty in performing experiments: irreversible pressure drops shall be distinguished from reversible pressure drops and measuring the pressure in narrow spaces and complex geometries is not easy. The influence of local velocities and of void fraction, other than the non-fully developed flow condition and the transient situation upon the adopted values of the coefficients, can be large and may require a broad range of experimental conditions.

The impact of the issue can be derived from the following: a) many of the discrepancies among results of application of SYS TH codes to target cases of interest obtained by different uses (either of the same code or of different codes) may originate from differences in 'fixing' the ' $\mathrm{K}$ factors'; b) in some cases, based on a comparison between experimental data and calculated results with detected unacceptable discrepancies, code models other than the formulas for pressure drops are modified to minimize those discrepancies without accounting for the effect of the arbitrarily fixed ' $\mathrm{K}$-factors'.

The proposals to address the issue are:

o An effort shall be made to develop traceable procedures for calculating local form loss coefficients in cases of interest to nuclear technology and/or supporting those procedures with a comprehensive data bank. Experiments and experimental conditions all over the world should be collected and archived. Examples for this could be the libraries for look-up tables for CHF and the microscopic XS (cross- section) for neutrons.

- CFD computational tools, primarily in single phase conditions, should be systematically used to generate proper values of $\mathrm{K}$-factor in the situations of interest for NPP. Specific attention shall be devoted to rounded or sharp edges.

2) The multi-D HTC surface

The convection heat transfer, i.e. one of the mechanisms for the transfer of thermal power between fluid and wall, is modeled by the well-established empirical relationship between the HTC and the heat flux. This gives rise to the current need to use around two dozen correlations to cover the ranges of interest in NPP design and NRS, noticeably including the consideration of phenomena like CHF, reflood (also characterized by the acronym RNB and by the MFB temperature), and condensation (also in the presence of non-condensable gases).

At least three fundamental issues of concern shall be identified in relation to the current status in predicting HTC:

a) The continuity among HTC values calculated from various correlations, namely at the boundaries of the respective validity ranges.

b) The repartition of heat flux from the wall to the fluid, distinguishing contributions to the gas and to the liquid phases and even directly (from wall) to the liquid-steam interface.

c) radiation heat transfer may have an important role associated with the Film Boiling heat transfer regime: contributions to the overall heat transfer by radiation and convection mechanisms may be difficult to distinguish.

The proposal here, related to the issue a), is to construct an as continuous as possible multi-dimensional (Multi-D) surface covering all the heat transfer regimes (examples of HT regimes are nucleate boiling, saturated boiling, film boiling) and all the flow regimes (example of flow regimes are bubbly, slug and annular flow). Reflood and condensation should be included in this picture. No proposal is formulated in relation to issues $\mathrm{b}$ ) and c).

3) Energy and Entropy balance following RCS blowdown and containment pressurization

The system of interest is a pressure vessel surrounded by a full pressure containment. The vessel is filled by high-pressure high temperature two-phase fluid and the containment is ideally isolated from the environment and filled by air at atmospheric conditions. The opening of a break in the pressure vessel triggers the "irreversible phenomenon" called blow-down or pressurized two-phase mixture discharge into the containment. Containment pressure increases and energy exchanges with the environment are (ideally) prevented. In this situation the entropy of the isolated system constituted by the vessel and the containment is expected to increase following the start of blow-down, i.e. an irreversible thermodynamic process for an isolated system. Results of code calculations are not consistent with what is expected. This constitutes the issue here. 
In the case of SYS TH codes the difficulty comes in estimating the energy flowing out of the break (TPCF model results can be qualified against experimental data; attaining the same qualification level is more complex in relation to the energy flow out of the break).

Additional issues (or sub-issues) connected with the above include:

a) Supersonic conditions. Supersonic conditions may occur in a discharge pipe (e.g. the line connecting the PORV with the sump or the ADS1-3 to the IRWST in the case of AP-1000 design). Pressure drops in the line, as well as loads upon the pipe and related mechanical constraints, are affected by the occurrence of supersonic conditions.

b) TPCF on-off. This is the situation which occurs when the pressure difference between upstream (RPV side) and downstream (containment side) is not enough to provoke critical flow at the assigned throat and cycles of TPCF and 'Bernoulli-flow' occur.

c) TPCF jumps. It has been known for decades that TPCF conditions in a nozzle may migrate (or jump) from one section to another. The same situation can be more complex inside a valve.

The capability to predict the discussed phenomena is not demonstrated. The recommendation here is to perform specific experiments and eventually to modify SYS TH codes.

4) Precision Targets

The word precision is not commonly used in the SYS TH area. Instead we commonly use accuracy and uncertainty, i.e. the known error resulting from the comparison between measured and calculated data, and the unknown error in NPP predictions, respectively. The word precision may be used to encompass both the words and the concepts of accuracy and uncertainty. No values for precision or precision targets are fixed by any institution (or by stakeholders identified in Table 1). So the common practice is to produce new codes or improved code versions without knowing the target for acceptability.

The recommendation is to solicit the issuance of precision targets in SYS TH which also should be moving targets associated with advancements in technology and in understanding.

5) The application of CFD-like approaches to NPP design and NRS technologies

CFD technology impacted the area of NPP technology and NRS since the 1990, as already mentioned. The code design targeting steady-state conditions, the lack of traceability of embedded equations (due to commercial reasons), the common assumption to neglect the pressure influence upon density changes, may represent serious obstacles for the application of CFD in nuclear areas. The quality assurance and the needs from the Defense In Depth (DID) impose the use of the best techniques (i.e. the least restrictive assumptions) and the possibility of 'independent' checks.

CFD codes for single-phase flows may be seen as part of a mature technology ready for applications even for NPP design and for NRS situations. The issue here is the qualification: a) Best Practice Guidelines, BPG, are available and may need enforcement and improvement; $b$ ) the convergence of results when the mesh sizes are decreased shall be demonstrated in any application; c) the demonstration of independence of results from mesh generation might be required.

A further issue is related to the coupling between CFD and SYS TH codes. The coupled computational tool may generate inconsistent results (e.g. in a closed NC loop partly modeled by SYS TH and by CFD codes): in fact CFD code results are (strongly) affected by BIC values at the boundaries of the CFD domain of integration which are necessarily approximate (otherwise full CFD modeling is needed).

A recommendation is to use CFD for the evaluation of local pressure drop, direct and reverse K-factors, item 1) above: properly qualified CFD codes and approaches to the application may be exploited to generate a databank for K-factors suitable for qualified SYS TH code applications.

Finally, CFD codes for two-phase flows are going to be developed. The full exploitation (the useful application) of the capabilities for those codes in NPP design and NRS may need decades or even never happen. Thus, two-phase CFD codes are not considered here as part of the needs in SYS TH (as already mentioned).

6) The thermal-hydraulics of passive systems

Passive systems and related thermal-hydraulics are part of the history for NPP design and NRS: the configuration of the RCS for both BWR and PWR (for instance) is determined considering the possibility to cool the core via Natural Circulation, at least removing decay heat. Passive ECCS like accumulators are installed in most NPP. The Chernobyl event in 1986 triggered new attention towards passive systems: new passive ECCS (i.e. other than accumulators) are part of NPP design, e.g. AP-1000, and passive phenomena are the basis of RCS operation, e.g. ESBWR. Passive systems are also used in the category of 'small' NPP, so-called SMR (Small and Medium Reactors).

A not-comprehensive list of issues connected with the design and the operation of passive systems (again not in the order of importance) is given below:

a) Stability of flow of two-phase mixture in a dozen meter high, large diameter riser of ESBWR.

b) Triggering of NC flow-rate, in some cases the consequence of opening of a valve: high values of flowrate may cause too fast cooling and large dynamic loads on the structures.

c) Stability issue: all NC systems are characterized by 'small' driving forces (i.e. small related to a possible similar system equipped with a centrifugal pump). 'Small' perturbations may challenge the stability. The stability issue is even more complicated for the category of NC systems where boiling and condensation occur. 
d) The stability issue for 'composite' systems: different NC systems are connected to each other either by a heat exchanger (series connection, e.g. passive cooling of SG when PS is working in NC) or they are hydraulically connected (parallel connection, e.g. PRHR, CMT and IRWST loops in AP-1000). The issue here is that the instability of one loop may propagate to connected loops: the stability issue must be addressed for the entire system.

e) The local pressure drop coefficients. The issue here, see also item 1) in the present list, is the precision needed for the 'K-factor' values: owing to the impact on stability (e.g. a 'cliff-edge' type of thermalhydraulic phenomenon) and to the 'small' driving forces available, a higher precision is needed for the 'K-factor' values than is needed for a system equipped with energized pumps. Then, the qualification of calculation results', without having access to suitable values for 'K-factors', may be questionable.

f) The reliability of passive systems constitutes a thermal-hydraulic issue not well established among designers of passive systems, e.g. ref. [34].

7) The scaling issue and experiments

Notwithstanding the large number of papers and reports related to scaling, 'scaling' still constitutes a controversy in SYS TH and in applications, e.g. see the paper at ref. [3]. The scaling issue in licensing is considered in ref. [3] and a roadmap for addressing the issue is proposed. Even though there is no common acceptance for the proposed roadmap, the reader can refer to this paper for details. The scaling issue for designing experiments is considered hereafter.

SETF and ITF shall be distinguished when addressing the scaling issue for experiments.

The SETF design as well as the design of SETF experiments may or may not be connected with scaling: rather, the need to characterize a TH phenomenon, coming from the process of code validation shall be the basis of the SETF design. So, the connection between scaling and SETF may be weak and will not be discussed further.

In the case of ITF a suitable design process shall include, particularly when the planned experiments are relevant for NRS, the consideration of principles like ALARA or the framework like DID. ALARA requires that the design effort be consistent with the safety relevance: in other words inadequacy of budget may not justify the construction of a 'very' (too) small facility or of a 'short' (reduced height) facility. The framework of DID demands providing proper consideration to (in this case 'the simulation of') parameters affecting the safety functions and the integrity of safety barriers. Then, 'the simulation of' PCT shall be considered a key target when designing ITF. This requirement may become more stringent when NC phenomena (or passive systems, see the item above) are involved in the simulation. The scaling-freedom in relation to the (design of a possible reduced) height for ITF offered by the so-called Ishiiscaling may be found to be inconsistent with the DID frame- work and the ALARA principle. Thus, basic limitations of Ishii-scaling (actually reduced height is an interpretation of the Ishii papers) are:

o There is no criteria to determine an acceptable 'shorter' length: i.e. to simulate 4 meters of active length for the reference core (prototype) height one can choose 3.9 meters or even 0.5 meters in the model;

oThe rod surface temperature cannot be simulated to the best when a shorter length is adopted because of the unknown relationship (object of the experimental campaign) between linear power, HTC and fluiddynamic conditions like local velocities and void fraction.

Scaling is closely connected with experiments. The issue here is the preservation of Experimental Data Base (EDB). Preservation of EDB implies the characterization of what must be preserved and the gathering of the data (indications for the process can be found in ref. [35]).

8) The V \& V for SYS TH codes

The V \& V applies to SYS TH codes and, as such, shall be considered a technological branch established for about thirty years. The precision targets, item 4) above, should be considered as a pre-requisite for V \& V (and part of the present $\mathrm{V} \& \mathrm{~V}$ issue, although this is distinguished here). Other aspects (i.e. other than precision targets) deal with the procedures for $\mathrm{V} \& \mathrm{~V}$ and with the comparison between calculated and experimental data.

An attempt to synthesize current V \& V understanding might be too long for the present paper. So, the issues, or the elements for reflections, are:

a) Matrices for Verification and Validation should be available as a complement to code development (i.e. developmental assessment matrices) and should be endorsed by the scientific community based on fulfillment of acceptability conditions.

a) Independent assessment matrices (i.e. matrices at the basis of code application), mostly dealing with Validation and not with Verification, should also be available based on requirements: the exploitation of those matrices should be the basis and the prerequisite for any code application to NRS problems.

The recommendation here is to pursue the development and the application of those matrices and to introduce acceptability requirements in connection with either the coverage-range of phenomena, [see also item 12) below], and the evaluation of comparison results coming from the use of the experimental part of the matrices [see also item 4) above].

\section{9) Uncertainty analysis}

The uncertainty needs come from the V \& V process. Evaluation of uncertainty must be connected with the application of BE SYS TH codes and must be supported by suitable Uncertainty Methods (UM). The process of combined application of a SYS TH code and an UM is called BEPU.

International projects like UMS, BEMUSE and 
PREMIUM are worthwhile to spread the expertise and shall be pursued. However, looking from the exterior, e.g. from the side of scientists not part of the working teams, it definitely may appear that those initiatives bring more questions than answers, or more doubts than solutions.

The elements for reflection (or the issues) are:

a) The correct interpretation of results from international projects.

b) The set-up and the acceptability of $\mathrm{V} \& \mathrm{~V}$ procedures for UM.

10) Coupling with SYS TH

Starting from the 1960s the fundamental disciplines for NPP design and NRS (see Introduction) followed separate paths for developments and related expertise was built in 'separate compartments'. To some extent this was also true in relation to SYS TH if one considers computational tools in the analysis sectors of transient RCS performance, core design (primarily aimed at nominal conditions), subchannel, and containment.

During the decade 1990-2000 the increase in computer power allowed numerical coupling among codes in different areas like structural mechanics, neutron physics, CFD and nuclear fuel, other than different branches in SYS TH. The SYS TH codes played a pivot role in this connection.

The coupling among codes implies addressing 'numerical and informatics' interfaces between the codes and the computer-compilers. Those interfaces are not necessarily homogeneous at the design level for different codes and generate issues connected with the transfer of information (data) among codes including the time step in transient calculations.

The elements for reflection and the recommendations are:

a) To merge in different-unique SYS TH code the capabilities of modeling RCS, core, sub-channel and containment: this brings the advantage of avoiding code coupling.

b) To propose systematic $\mathrm{V} \& \mathrm{~V}$ procedures for coupling, also involving acceptance criteria for the coupled results (e.g. see ref. [22] in relation to the coupling between SYS TH and 3D NK codes).

See also CFD coupling under item 5) above.

11) Modeling and structure for computational tools

The structure and the modeling of existing TH SYS codes (or computational tools) is based on the application of the 'six-partial-derivative-balance-equations' to simulate the transient performance of the two-phase mixtures. Those equations shall be seen as the result of the application of the principles of thermodynamics and of mechanics. However, approximations or even inadequacies (so far unavoidable) are part of the structure and of the modeling, like (more details can be found in ref. [36]):

- Two phase flow regimes are not directly accounted for.

- Averaging is needed at the levels of cross section flow area, integration volume, and time; all of this is associated with the concept of Control Volume.
- Consideration of two (or three) fluid fields as a solution domain (this may be seen as a consequence of the two items above).

- The need for a variety of constitutive and(/or) closure equations which are unavoidably used outside their range of applicability; this also implies the need for 'virtual correlations' (or numerical terms) to get solutions within the real domain.

The concept of Control Volume implies the need to reconstruct the continuous reality (i.e. the NPP configuration) by more or less large pieces, thus introducing undue discontinuities at the connection faces. The well-known issue of 'water-packing' is a consequence.

$\mathrm{V} \& \mathrm{~V}$, with main reference to Validation, shall be seen as the only way to make acceptable those inadequacies.

Nevertheless, the SYS TH codes shall be seen as the basket for the expertise gathered in the areas of modeling and experiments. Validation has been, and actually is, the key to overcome the modeling approximations. From pursuing the validation process one shall recognize that errors exist in the results from code application and one shall be capable to quantify those errors: this imposes, among other things, the need to estimate the uncertainty [see also item 9)].

The recommendation here is a systematic effort to characterize the listed deficiencies, also including a detailed evaluation of their impact upon the results. The items above, e.g. items 1), 2) and 3), are applicable in this connection. The same recommendation also constitutes the target of the international network for code developers, FONESYS, recently established (search for FONESYS in the web associated with the words thermal-hydraulic code).

12) Licensing needs

Licensing can be seen as the legal part of NRS and also as the exit edge for NRS findings and requirements.

Accident analysis constitutes an important part of the licensing. Design Basis Accident (DBA), Anticipated Operational Occurrence (AOO), Beyond DBA (BDBA) as well as Emergency Operating Procedure (EOP) and Accident Management Guidelines (AMG) constitute established concepts in accident analysis. Following the start of any accident (e.g. a PIE part of the DBA envelope) the I \& C has the potential to bring the NPP far from the initial condition, e.g. ref. [37].

The first element for reflection for accident analysis deals with the use of conservatism in input data. The conservatism in input data, also known as "Option 2" in IAEA documents, see e.g. refs. [26] and [27], does not ensure conservatism in the output (or code calculation results). Conservatism in the output can only be demonstrated when BEPU analyses are performed; otherwise adequacy of conservatism on the output can only be inferred by deep expertise, when this is available. 'Option 2' should be considered as an 'interim' option in the history of application of SYS YH codes to licensing.

The key issue in the case of accident analysis in licens- 
ing is the application of the BEPU approach, also identified as "Option 3" in the IAEA documents, see e.g. refs. [26] and [27]. Pioneering efforts have been completed in this direction as discussed under the historic outline above. However, developments are needed to make the regulatory process traceable and robust by addressing sub-issues like:

- use of 3D NK to determine the maximum linear power of individual fuel rods,

- use of 3D NK to perform the transient analysis of events where non-homogeneous core behavior is expected,

- consideration of single failure,

- consideration of the availability of systems and components part of the NPP (noticeably including ESF),

- BEPU analysis of transients or situations identified as ATWS, SBO and PTS,

- establish procedures for determining the worst break position and, at a higher level of detail, the break opening time which affects the calculation of mechanical load on internal and external components and structures,

- establish procedures to account for the impact of burnup upon the transient analysis,

- establish procedures to calculate the quantities affecting the acceptance criteria other than the PCT and the $\mathrm{H} 2$ production, i.e. the demonstration of core remaining intact (mostly mechanical loads at the transient start in case of LBLOCA) and the long term core cooling involving the specific sub-issues of sump-recirculation, debris-effect and, where applicable, containment leakages and long term condensation.

Further recommendations are:

a) A procedure shall be established connecting accident analysis with the design and the applicability domain of system codes: DBA envelope $\rightarrow$ TH phenomena $\rightarrow$ significant physical quantities (e.g. pressure, heat flux, flow-rate) $\rightarrow$ range of variations for those quantities and related combinations $\rightarrow$ design domain and V \& V domain for SYS TH codes.

b) I \& C simulation shall be part of the analysis of accidents.

The recommendation a) also applies under item 8) 'The V \& V for SYS TH Codes'. The recommendation b) also applies under item 13) 'PSA and SYS TH'.

13) PSA and SYS TH

Probabilistic Safety Assessment (PSA) process at any of the Levels 1, 2 or 3, requires deterministic calculations to establish the success of any sequence, to decide about the failure modes of systems structures and components and to estimate the 'source term'. Historically, approaches and computational tools have been adopted for deterministic calculations which are simplified in relation to the methods and the numerical codes available within the SYS TH domain (the reason for this being the huge number of requested calculations).

The role of I \& C in PSA constitutes an additional concern. The I \& $\mathrm{C}$ systems and components are designed with the target of being un-influential or of providing benefits after any Postulated Initiating Event (PIE). However, the complexity of the entire NPP system and the interaction among various logics and components following any PIE, has the potential to bring the NPP configuration far from the configuration existing at the time of the PIE.

The issues or the elements for reflection are:

a) The design of complex EOP and SAMG on the one hand and the availability of UM on the other hand, together with the advent of more and more powerful computers, lead to reconsidering the use of simplified approaches when estimating the success of any sequence or when calculating radiological releases. This may imply the need for huge computational resources.

b) The role of 'deterministic' uncertainty shall be included in probabilistic results.

c) The I \& C simulation shall be considered for PSA (this recommendation also applies under the item 'Licensing' above, related to DSA).

14) Severe Accident and SYS TH

Making reference to the predicted evolution of any accident, the intact (or nearly intact) core geometry is normally taken as the boundary between SYS TH and SA analyses.

The quality of DBA analyses (or of analyses performed within the DBA envelope) shall be distinguished from the quality of SA analyses or analyses involving core degradation. Enormous progress has been made during the last two decades in the understanding of SA phenomena; however, the qualification level of results from SA analyses shall be considered far lower than the qualification level expected or achieved in the area of SYS TH analyses.

Therefore the design impact from SA analyses shall be avoided or minimized; rather SA analyses shall be used as support for improving the current understanding. New systems to mitigate SA conditions seem improper and not in the direction of facilitating the operator actions and, even worse, can be the origin of new accident sequences (e.g. the undue flooding of a reactor cavity during nominal operation).

Recommendations or elements for reflection are:

a) The analysis until the prediction of important core degradation shall be performed by the BE SYS TH code. This is specifically true in relation to the calculation of the time of occurrence of degraded core conditions: in other words, the use of simplified approaches connected with SA analysis might produce misleading results far from what can be reliably obtained by the BEPU approach.

b) SA code results properly supported by SYS TH code results can be relevant for planning operator actions: optimized SAMG and connected procedures can be designed.

c) Impact on the NPP hardware design from SA code 
results, even supported by SYS TH codes, should be avoided owing to the low qualification level, as already mentioned. Furthermore design changes caused by SA analyses should imply changes in the licensing approach which currently distinguishes between DBA and BDBA: the DBA envelope shall be changed according to the design and proper quality level should be ensured for SA computational tools. 15) User effect and training

The current user effect in the application of SYS TH codes and coupled codes undermines the applicability of those codes and the trust toward the derived calculation results and toward the possible benefits from those applications (e.g. see refs. [10], [11], [12] and [23]).

The effect of code-users upon "poor" code calculation results shall be seen as similar to the effect of inexperienced drivers crashing a top-quality bus or truck against a wall or off the road. In these cases (truck or bus off-road), little or no blame is put on the truck makers or designers and discipline and training is invoked for drivers. In the case of SYS TH code, poor code calculation results are preferably attributed to poor code capabilities: codes appear unreliable and code development processes become repetitive and never-ending. Elements for reflections are discussed below.

More focus should be on the qualification of researchers in the SYS TH area and additional emphasis should be given to the requested (mainly from the side of regulators) qualification level of code users. International programs are on-going in this direction, e.g. ref. [23], but they still appear weak and not properly supported by regulatory authorities. Targets and accomplishments for code users shall be connected with the number of years of experience and with the modalities of performing the analysis. The role of the input deck, or the interface between the NPP reality and the code, should receive proper attention. Specific recommendations are:

- The input deck or the nodalization developed by group 1 of code-users should be 'independently checked' by group 2 of code users.

- Proper acceptance criteria shall be used to endorse the quality of any input deck.

- The results of any safety or design relevant calculation should be 'independently checked' and approved by a 'supervisor' having at least ten years documented expertise in SYS TH analyses.

- In addition to uncertainty analysis needed in conjunction with any BE code calculation, properly planned sensitivity analyses are necessary to minimize the risk of neglecting possible bifurcation or cliff-edge effects.

A synthesis of the items above is provided in Table 2. The following modalities or areas are proposed to plan possible improvements (third column in Table 2):

$\Rightarrow$ The SYS TH code: this implies that improvements are expected for the codes and includes the (fundamental) modeling.

$\Rightarrow$ Modeling: this implies that fundamental processes, or basic research, or experimental data are needed. $\Rightarrow$ Application: this deals with modalities and requirements for the processes and the procedures which foresee the application of computational tools and data to the NPP design, safety or licensing. The word Application is adopted here to signify 'exploitation of achieved knowledge and understanding in the technological practice'.

$\Rightarrow$ Design: this implies that improvements are expected in the design of thermal-hydraulic systems.

$\Rightarrow$ ITF design: this implies that improvements (or acceptable strategies) are expected in the design of new ITF.

$\Rightarrow$ EDB: this should be taken as a synonymous of EDB preservation and implies that investments are expected in the area of preserving and storing experimental data.

It shall be noted how SYS TH code is both a target for improvement and a way to pursue envisaged improvements.

\section{CONCLUSIONS}

A non-comprehensive and non-systematic review of perspectives and proposals for future activities in system thermal-hydraulics (SYS TH) has been performed and is applicable to NPP design and Nuclear Reactor Safety frameworks. 'Elements for reflection' are presented in the paper.

Numerical codes and experimental facilities and the associated research programs and/or related data and applications, constitute the hearth for SYS TH: the identification of numerical codes and of experimental programs is provided in section 2.2 and repeated in the List of Acronyms below.

A spot historic review brought to emphasize the publication of the Interim Acceptance Criteria for the design of ECCS, US NRC in 1971, as the triggering event for the development of SYS TH. Other milestones are the achievement of qualification for SYS TH codes and their use inside the BEPU approach together with Uncertainty Methods.

Fifteen items are discussed in the paper and shall be seen as the 'elements for reflection'. These are reported in alphabetic order hereafter making reference to the key words in Table 2:

- Computational Fluid-Dynamics (CFD) Role for NPP

Design and Nuclear Reactor Safety.

- Coupling (with SYS TH Codes).

- Licensing (implying application of SYS TH Codes).

- Local Form Loss Coefficients, 'K-Factors'.

- Modeling and Structure (of SYS TH codes)

- Multi-D Heat Transfer Coefficient (HTC) Surface.

- Passive Systems.

- Precision Targets.

- Probabilistic Safety Assessment (connection with SYS TH Code application) 
Table 2. Synthesis of (Personal) Views for Perspectives in System Thermal-Hydraulics

\begin{tabular}{|c|c|c|c|}
\hline $\begin{array}{l}\text { Topic } \\
\text { No }\end{array}$ & $\begin{array}{l}\text { Category / Target for } \\
\text { Improvement }\end{array}$ & $\begin{array}{l}\text { Modality for } \\
\text { Improvement }\end{array}$ & Proposals/Notes \\
\hline 1 & $\begin{array}{c}\text { Local 'Form Loss' } \\
\text { Coefficients - K-Factors }\end{array}$ & Modeling & $\begin{array}{l}\text { Libraries shall be created with similar complexity as the ones for neutron } \\
\text { microscopic XS. }\end{array}$ \\
\hline 2 & Multi-D HTC Surface & Modeling & $\begin{array}{l}\text { Either a new approach for calculating wall-to-fluid HT, or a suitable } \\
\text { multi-D surface for HTC. }\end{array}$ \\
\hline 3 & $\begin{array}{l}\text { RCS Depressurization } \\
\& \text { CO Pressurization }\end{array}$ & SYS TH code & New experiments may be needed. \\
\hline 4 & Precision Targets & Application & Precision targets shall be established (also part of V \& V). \\
\hline 5 & $\begin{array}{l}\text { CFD Role for NPP } \\
\text { Design and NRS }\end{array}$ & Application & Specific V \& V needed, including improved BPG. \\
\hline 6 & Passive Systems & Design \& SYS TH code & Specific experiments needed, addressing the stability issue. \\
\hline 7 & Scaling \& Experiments & ITF design \& EDB & $\begin{array}{c}\text { The scaling issue in licensing is addressed in ref. [3]. Scaling for } \\
\text { experiments is discussed here. 'Full' height ITF may be needed. EDB to } \\
\text { be properly stored. }\end{array}$ \\
\hline 8 & $\mathrm{~V} \& \mathrm{~V}$ & Application & $\begin{array}{l}\text { Establishing Developmental and Independent Assessment Matrices. } \\
\text { Connected with items 4) \& 12). }\end{array}$ \\
\hline 9 & Uncertainty Methods & Application & Feedback from international projects. Specific V \& V needed. \\
\hline 10 & Coupling & Application & Numeric and informatics issues. Specific V \& V needed. \\
\hline 11 & Modeling \& Structure & $\begin{array}{l}\text { Modeling \& } \\
\text { SYS TH code }\end{array}$ & Inadequacies of SYS TH codes. FONESYS network established. \\
\hline 12 & Licensing & $\begin{array}{l}\text { SYS TH code \& } \\
\text { Application }\end{array}$ & $\begin{array}{l}\text { Comprehensive BEPU approach. Licensing at the origin of the } \\
\text { applicability range for SYS TH code (also part of V \& V). Consideration } \\
\text { of I \& C. }\end{array}$ \\
\hline 13 & PSA Connection & Application & $\begin{array}{c}\text { Consideration of complexities in SYS TH including uncertainty. } \\
\text { Consideration of I \& C. }\end{array}$ \\
\hline 14 & Severe Accident & $\begin{array}{l}\text { Design \& } \\
\text { Application }\end{array}$ & $\begin{array}{l}\text { Current qualification level far below SYS TH. Design of optimized } \\
\text { SAMG expected. }\end{array}$ \\
\hline 15 & User Effect & Application & Code-user role. Training and qualification needed. \\
\hline
\end{tabular}

- Reactor Coolant System (RCS) Depressurization \& Containment Pressurization.

- Severe Accident (connection with SYS TH Code application)

- Scaling \& Experiments.

- Uncertainty Methods.

- User Effect (and user training-qualification).

- Verification \& Validation (V \& V).

Arbitrariness in the use of direct and reverse local pressure drop coefficients ('K-factors') and the inadequate qualification of code users so far undermined the confidence for the application of currently available SYS TH codes.

Procedures shall be established in a number of areas (identified as Applications in Table 2) which are consistent with the present level of knowledge, in order to make the results from SYS TH code calculations robust and reproducible. The BEPU (Best Estimate Plus Uncertainty) approach noticeably falls in this category. 'Closing the issue' in areas like Validation (rather than V \& V), Scaling and application of Uncertainty Methods is also deemed possible based on the current understanding: spreading of available information within the scientific community may be worthwhile to reach consensus.

Improvements are considered necessary in areas like selected phenomena modeling, coupling among codes in different disciplines, the design of passive systems and the evaluation of related reliability, the interface between probabilistic and the deterministic safety assessment, andthe application of Computational Fluid-Dynamics (CFD) codes. A peculiar area which deserves proper attention is the code-user training and qualification.

From a global perspective viewpoint, the results from envisaged activities should converge for a more efficient licensing process (and a better NPP design), minimizing the unavoidable lag between scientific and technological achievements and their practical applications. 


\section{ACKNOWLEDGEMENT AND NOTES FROM THE AUTHOR}

This paper was stimulated by Prof. Jae Jun Jeong, a friend and a prominent scientist formerly at KAERI and presently at Pusan National University in South Korea. I cannot be sure to have met his expectations, however I am indebted very much to him for being confident in the value of the paper.

I regret that the historical perspective may appear partial and subjective, even though I did my best to identify the most relevant topics and to minimize reference to my own activity. I also regret that the list of references is necessarily incomplete: a suitable list, consistent with the topics quoted in the paper would have required more than 200 items. In this connection, the web can be of enormous help for those readers interested in the key-words mentioned in this paper. Finally, extensive use is made of acronyms and many of these, for the sake of effectiveness, are not explicated in the paper and are only reported in the List of Acronyms below: I apologize for this.

\section{List of Acronyms}

\section{ADS}

AEC

ALARA

AM

AMG

ANE

ANS

AOO

APEX

APROS

AP600, AP-1000

ASME

ATHLET

ATLAS

ATWS

BDBA

$\mathrm{BE}$

BEAU

BEMUSE

BEPU

BETHSY

BIC

BPG

BWR

CANDU

CASL

CATHARE

CCFL

CCTF
= Automatic Depressurization System

$=$ Atomic Energy Commission (see US NRC)

= As Low As Reasonably Achievable

$=$ Accident Management

$=$ Accident Management Guidelines

$=$ Annals of Nuclear Energy (Journal)

$=$ American Nuclear Society

= Anticipated Operational Occurrence

= Name of ITF in US

$=$ SYS TH code developed in Finland

$=$ Reactor designed by Westinghouse

$=$ American Society of Mechanical Engineers

= SYS TH code developed in Germany

= Name of ITF in Korea

= Anticipated Transient Without Scram

$=$ Beyond DBA

$=$ Best Estimate - also acronym for a series of Conferences

$=$ Best Estimate Analysis and Uncertainty

$=$ Project in area of uncertainty launched and completed by CSNI

$=$ Best Estimate Plus Uncertainty

$=$ Name of ITF in France

$=$ Boundary and Initial Conditions

$=$ Best Practice Guidelines

$=$ Boiling Water Reactor

$=$ Reactor designed by AECL in Canada

$=$ DOE project

$=$ SYS TH code developed in France

$=$ Counter Current Flow Limitation

= Name of large scale SETF in Japan
CCVM

CFD

CFR

$\mathrm{CHF}$

CIAU

CMT

$\mathrm{CO}$

CRP

CRUD

CSAU

CSNI

DBA

DID

DNB

DOE

DSA

EC

ECCS

EDB

EdF

EOP

EPRI

ESBWR

ESF

ETFS

ETN

EUROFASTNET $=$ EC network for planning TH project

FIST

FIX-II

FONESYS

FSAR

GIRAFFE

GRNSPG

HDR

H-F

HT

HTC

IA

IAC

IAEA

IJMF

IRWST

ISB

ITF

I \& C

JHT

$=$ Computer (or CSNI) Code Validation Matrix

$=$ Computational Fluid-Dynamic

$=$ Code of Federal Regulation

$=$ Critical Heat Flux

= Code with Capability of Internal Assessment of Uncertainty

$=$ Core Make-up Tank

$=$ Containment

= Co-ordinated Research Project (inside IAEA)

$=$ Chalk River Unidentified Deposit

$=$ Code Scaling Applicability and Uncertainty

$=$ Committee on the Safety of Nuclear Installations of NEA

$=$ Design Basis Accident

$=$ Defense in Depth

$=$ Departure from Nucleate Boiling

$=$ see US DOE

$=$ Deterministic Safety Assessment (or Analysis)

$=$ European Commission

$=$ Emergency Core Cooling Systems

$=$ Experimental Data Base

$=$ Nuclear Utility in France

$=$ Emergency Operating Procedures

$=$ Electrical Power Research Institute

$=$ Reactor designed by General Electric

$=$ Engineered Safety Features

$=$ Experimental Thermal and Fluid Science (Journal)

$=$ Nuclear Utility in Brasil

$=$ Name of ITF in US

$=$ Name of ITF in Sweden

$=$ Network of SYS TH code developers (see the web)

$=$ Final Safety Analysis Report

$=$ Name of ITF in Japan

$=$ Nuclear Research Group in San Piero a Grado

= Name of large scale SETF in Germany

$=$ Henry-Fauske (TPCF model)

$=$ Heat Transfer

$=$ Heat Transfer Coefficient

$=$ Interfacial Area

$=$ Interim Acceptance Criteria

= International Atomic Energy Agency

$=$ International Journal on Multiphase Flow

$=$ In-Reactor Water Storage Tank

$=$ Name of ITF in Russia

$=$ Integral Test Facility

$=$ Instrumentation and Control (systems)

$=$ Journal of Heat Transfer (of ASME) 


\begin{tabular}{|c|c|}
\hline KAERI & $\begin{array}{l}=\text { Korea Atomic Energy Research } \\
\text { Institute }\end{array}$ \\
\hline KORSAR & $=$ SYS TH code developed by Russia \\
\hline LBLOCA & $=$ Large Break LOCA \\
\hline LOCA & $=$ Loss of Coolant Accident \\
\hline LOBI & $=$ Name of ITF of EC installed in Italy \\
\hline LOFT & $=$ Name of ITF in US \\
\hline LSTF & $=$ Name of ITF in Japan \\
\hline LUT & = Look-Up Tables (for CHF) \\
\hline MARS & = SYS TH code developed in Korea \\
\hline MARVIKEN & $=$ Name of large scale SETF in Sweden \\
\hline MIST & $=$ Name of ITF in US \\
\hline NASA & $=$ Nuclear Utility in Argentina \\
\hline $\mathrm{NC}$ & $=$ Natural Circulation \\
\hline NEA & $=$ Nuclear Energy Agency of OECD \\
\hline NED & $=\underset{(\text { Journal })}{\text { Nuclear Engineering and Design }}$ \\
\hline NET & $=\underset{(\text { Journal) }}{\text { Nuclear Energy and Technology }}$ \\
\hline NK & $=$ Neutron Kinetics \\
\hline NPP & $=$ Nuclear Power Plant \\
\hline NRC & $=$ see US NRC \\
\hline NRS & $=$ Nuclear Reactor Safety (technology) \\
\hline NSC & $=$ Nuclear Science Committee of NEA \\
\hline NT & $=$ Nuclear Technology (Journal of ANS) \\
\hline NURESAFE & $=$ EC project follow-up of NURISP \\
\hline NURESIM & $\begin{aligned}= & \text { EC planning project based on EURO- } \\
& \text { FASTNET }\end{aligned}$ \\
\hline NURETH & $\begin{aligned}= & \text { Nuclear Reactor Thermal-hydraulics } \\
& \text { (series of ANS conferences) }\end{aligned}$ \\
\hline NURISP & $=$ EC project follow-up of NURESIM \\
\hline OECD & $\begin{aligned}= & \text { Organization for Economic Coop- } \\
& \text { eration and Development }\end{aligned}$ \\
\hline PACTE & $=$ Name of ITF in Finland \\
\hline PANDA & $\begin{aligned}= & \text { Name of large scale SETF in Switzer- } \\
& \text { land }\end{aligned}$ \\
\hline PIE & $=$ Postulated Initiating Event \\
\hline PIPER-ONE & $=$ Name of ITF in Italy \\
\hline PIRT & $\begin{aligned}= & \text { Phenomena Identification and Ranking } \\
& \text { Table }\end{aligned}$ \\
\hline PKL & $=$ Name of ITF in Germany \\
\hline PMK & $=$ Name of ITF in Hungary \\
\hline PNE & $=$ Progress in Nuclear Energy (Journal) \\
\hline PORV & $=$ Pilot Operated Relief Valve \\
\hline PREMIUM & $\begin{aligned}= & \text { Project in area of uncertainty launched } \\
& \text { by CSNI }\end{aligned}$ \\
\hline PRHR & $\begin{aligned}= & \text { Pressurized Residual Heat Removal } \\
& \text { (system) }\end{aligned}$ \\
\hline PS & $=$ Primary System \\
\hline PSA & $\begin{aligned}= & \text { Probabilistic Safety Assessment (or } \\
& \text { Analysis) }\end{aligned}$ \\
\hline PSB & $=$ Name of ITF in Russia \\
\hline PTS & $=$ Pressurized Thermal Shock \\
\hline PUMA & $=$ Name of large scale SETF in US \\
\hline PWR & $=$ Pressurized Water Reactor \\
\hline RCS & $=$ Reactor Coolant System \\
\hline
\end{tabular}

\begin{tabular}{|c|c|}
\hline RD-14M & $=$ Name of ITF in Canada \\
\hline RELAP & $=$ SYS TH code developed in US \\
\hline RG & $=$ Regulatory Guide (of US NRC) \\
\hline ROSA-III & $=$ Name of ITF in Japan \\
\hline RPV & $=$ Reactor Pressure Vessel \\
\hline $\mathrm{R} \& \mathrm{D}$ & $=$ Research and Development \\
\hline SAMG & $\begin{aligned}= & \text { Severe Accident Management Guide- } \\
& \text { lines }\end{aligned}$ \\
\hline SBLOCA & $=$ Small Break LOCA \\
\hline SBO & $=$ Station Blackout \\
\hline SBWR & = see ESBWR \\
\hline SCTF & $=$ Name of large scale SETF in Japan \\
\hline SEMISCALE & $=$ Name of ITF in US \\
\hline SETF & $=$ Separate Effect Test Facility \\
\hline SG & $=$ Steam Generator \\
\hline SILENCE & $\begin{aligned}= & \text { Network of SYS TH experimentalists } \\
& \text { (see the web) }\end{aligned}$ \\
\hline SMR & $=$ Small and Medium Reactor \\
\hline SOAR & $=$ State of the Art Report \\
\hline SPACE & $=$ SYS TH code developed in Korea \\
\hline SPES & $=$ Name of ITF in Italy \\
\hline SRS & $=$ Safety Report Series (of IAEA \\
\hline SSG & $=$ Specific Safety Guide (of IAEA) \\
\hline STNI & $\begin{aligned}= & \text { Science and Technology of Nuclear } \\
& \text { Installations (Journal) }\end{aligned}$ \\
\hline SYS TH & = System Thermal-Hydraulics \\
\hline TECC & $=$ Thermal-Hydraulics of ECCS \\
\hline THTF & $=$ Name of large scale ITF in US \\
\hline $\mathrm{TF}$ & $=$ Test Facility \\
\hline TM & $=$ Technical Meeting (of IAEA) \\
\hline ТPCF & $=$ Two Phase Critical Flow \\
\hline TPPD & $=$ Two Phase Pressure Drop \\
\hline TRACE & $=$ SYS TH code developed in US \\
\hline UM & $=$ Name of ITF in US \\
\hline UMAE & $\begin{aligned}= & \text { Uncertainty Methodology based on } \\
& \text { Accuracy Extrapolation }\end{aligned}$ \\
\hline UMS & $\begin{aligned}= & \text { Project in area of uncertainty launched } \\
& \text { and completed by CSNI }\end{aligned}$ \\
\hline UPTF & $=$ Name of large sale SETF in Germany \\
\hline US DOE & $=$ US Department of Energy \\
\hline US NRC & $=$ US Nuclear Regulatory Commission \\
\hline VVER-1000 & $\begin{aligned}= & \text { Reactor designed by Gidropress in } \\
& \text { Russia }\end{aligned}$ \\
\hline V \& V & $=$ Verification and Validation \\
\hline XS & $=$ Cross Section \\
\hline W-Gama & $=$ Working group inside CSNI \\
\hline & $=$ Three-Dimensional \\
\hline
\end{tabular}

\section{REFERENCES}

[1] USNRC, Code of Federal Regulation, Washington (US) [continuously updated - see the website of US NRC].

[2 ] IAEA, Accident Analysis for Nuclear Power Plants, IAEA Safety Reports Series No 23, ISSN 1020-6450; ISBN 920-115602-2, Vienna (A), 2002.

[3] D’Auria F., Galassi G.M., Scaling in nuclear reactor system thermal-hydraulics, J. Nucl. Eng. Des. 240 (10), 
3267-3293, 2010.

[4] OECD/NEA/CSNI, CSNI Code Validation Matrix of Thermo-Hydraulic Codes for LWR LOCA and Transients, CSNI, 132, Paris, France, 1987

[5] OECD/NEA/CSNI, CSNI Code Validation Matrix of Thermo-Hydraulic Codes for LWR LOCA and Transients. CSNI Report, 132-rev.1, Paris, France, 1996

[6] OECD/NEA/CSNI, Separate Effects Test Matrix for Thermal-Hydraulic Code Validation: Phenomena Characterization and Selection of Facilities and Tests, OCDE/GD (94)82, Paris, France, 1993.

[7] US AEC, Interim Acceptance Criteria (IAC) for ECCS, USAEC, Washington (DC), USA, 1971.

[ 8 ] USNRC, WASH-1400, NUREG-75/014, Washington (DC), USA, 1975.

[9] D’Auria F., Galassi G.M., Code validation and uncertainties in system thermal-hydraulics, J. Progress in Nuclear Energy, 33(1/2), 175-216, 1998.

[10] Aksan S.N., D'Auria F., Staedtke H., User effects on the thermal-hydraulic transient system codes calculations, J. Nuclear Engineering and Design 145 (1 and 2), 1993.

[11] Ashley R., El-Shanawany M., Eltawila F., D’Auria F, Good Practices for User Effect Reduction, OECD/CSNI Report NEA/CSNI/R(98)22,Paris(F) 1998.

[12] D'Auria F., Proposal for training of thermal-hydraulic system codes users, IAEA Spec. Meet. On User Qualification and User Effects on Accident Analysis for Nuclear Power Plants, Vienna (A), 1998.

[13] Bonuccelli M., D’Auria F., Debrecin N., Galassi G.M., A methodology for the qualification of thermal-hydraulic codes nodalizations, International Top. Meet. On Nuclear Reactor Thermal-Hydraulics (NURETH-6), Grenoble, France, 1993.

[14] Damerell P.S., Simons J.W., 2D/3D Program Work Summary Report, GRS Report No 100, ISBN 3-923875-50-9, Koln (G), 1992.

[15] USNRC, Quantifying Reactor Safety Margins: Application of CSAU to a LBLOCA NUREG/CR-5249, USNRC, Washington, DC, USA, 1989.

[16] Hofer E., The GRS programme package for uncertainty and sensitivity analysis. In: Seminar on Methods and Codes for Assessing the Off-site Consequences of Nuclear Accidents, EUR 13013, CEC, Bruxelles (Belgium), 1990.

[17] D'Auria F., Debrecin N., Galassi G.M., Outline of the uncertainty methodology based on accuracy extrapolation (UMAE), J. Nucl. Technol. 109 (1), 21-38, 1995.

[18] OECD/NEA CSNI [Authors: Wickett, T. (Ed.), D'Auria, F., Glaeser, H., Chojnacki, E., Lage, C. (Lead Authors), Sweet, D., Neil, A., Galassi, G.M., Belsito, S., Ingegneri, M., Gatta, P., Skorek, T., Hofer, E., Kloos, M., Ounsy, M., Sanchez, J.I.]. Report of the Uncertainty Methods Study for advanced best estimate thermal-hydraulic code applications - Vols. I \& II. OECD/CSNI Report NEA/CSNI/R(97)35, Paris (F), June 1998.

[19] USNRC, Best-Estimate Calculations of Emergency Core Cooling System Performance, USNRC Regulatory Guide 1.157, 1989.

[20] D’Auria F., Giannotti W., Development of code with capa- bility of internal assessment of uncertainty. Nuclear Technology 131(1), 159-196, 2000.

[21] Yadigaroglu G., Andreani M., Dreier J., Coddington P., Trends and needs in experimentation and numerical simulation for LWR safety, J. Nucl. Eng. Des. 221, 205-223, 2003

[22] OECD/NEA, Neutronics/Thermal-hydraulics Coupling in LWR Technology - Three vols. OECD/NEA Report No 4452, ISBN 92-64-02083-7, Paris (F), 2004, (Vol. I, 103 pages)

[23] Petruzzi A., D’Auria F., Bajs T., Reventos F., International Training Program: 3D S.UN.COP-Scaling. Uncertainty and 3D thermal-hydraulics/neutron-kinetics CouPled Codes Seminar. ENC, Versailles, France, 2005.

[24] KWU-Siemens, FSAR: Final Safety Analysis Report Central Nuclear Almirante Álvaro Alberto, Unit 2 - Rev. 0 , Sept. 1997

[25] US NRC, Transient and Accident Analysis Methods. RG 1.203, USNRC, Washington, USA, 2005.

[26] IAEA, Best Estimate Safety Analysis for Nuclear Power Plants: Uncertainty Evaluation, IAEA Safety Report Series, No 52, Vienna (A), 2008

[27] IAEA, Deterministic Safety Analysis for Nuclear Power Plants, IAEA SSG-2, Vienna, Austria, 2010.

[28] ANS, Int. Meet. on Best-Estimate Methods in Nuclear Installation Safety Analysis (BE-2000), Washington, DC (US), 10-13 Nov. 2000.

[29] ANS, Int. Meet. on Best-Estimate Methods in Nuclear Installation Safety Analysis (BE-2004) Washington, DC (US), 14-18 Nov. 2004.

[30] Abdul-Razzak A., Guidelines for application of the Best Estimate Analysis and Uncertainty (BEAU) methodology to licensing analysis in the Canadian CANDU Nuclear Power Industry, IAEA TM, “Application of Deterministic Safety Analysis, Pisa (I), 21-29 Sept. 2009.

[31] Glaeser H., GRS method for uncertainty and sensitivity evaluation of code results and applications .Journal of Science and Technology of Nuclear Installations, 2008

[32] UNIPI-GRNSPG, A Proposal for Performing the Atucha II Accident Analyses for Licensing Purposes - The BEPU Report - Rev. 3 , Pisa (I) 2008 [endorsed by Regulatory Authority in Argentina].

[33] Zuber N., Scaling: from Quanta to Nuclear Reactors, J. Nucl. Eng. Des. 240, 1986-1996, 2010.

[34] Jafari J., D’Auria F., Kazeminejad H., Davilu H., Reliability evaluation of a natural circulation system. J. Nuclear Engineering and Design 224,79-104, 2003.

[35] Petruzzi A., Fiori F., Kovtonyuk A., D’Auria F., Supporting qualified database for uncertainty evaluation, Proceeding of ICAPP 2012, Chicago, June 24-28, 2012, paper No 12085.

[36] D'Auria F., Chojnacki E., Glaeser H., Lage C., Wickett T., Overview of Uncertainty Issues and Methodologies, Invited at OECD/CSNI Seminar on Best Estimate Methods in Thermal-Hydraulic Analyses - Ankara (Tr) June 29 -July $1,1998$.

[37] D’Auria F., Camargo C., Muellner N., Lanfredini M., Mazzantini O., The simulation of I \& $\mathrm{C}$ in accident analyses of nuclear power plants, J. Nuclear Engineering and Design 250, 656-663, 2012. 